\title{
Dietary arginine affects energy metabolism through polyamine turnover in juvenile Atlantic salmon (Salmo salar)
}

\author{
Synne M. Andersen ${ }^{1 *}$, Elisabeth Holen ${ }^{1}$, Anders Aksnes ${ }^{2}$, Ivar Rønnestad ${ }^{3}$, Jens-Erik Zerrahn ${ }^{4}$ \\ and Marit Espe ${ }^{1}$ \\ ${ }^{1}$ National Institute of Nutrition and Seafood Research (NIFES), PO Box 2029, N-5817 Bergen, Norway \\ ${ }^{2}$ Ewos Innovation As, $N-4335$ Dirdal, Norway \\ ${ }^{3}$ Department of Biology, University of Bergen, Bergen, Norway \\ ${ }^{4}$ Evonik Degussa International AG, 7100 Vejle, Denmark
}

(Submitted 18 January 2013 - Final revision received 12 March 2013 - Accepted 5 April 2013 - First published online 9 May 2013)

\begin{abstract}
In the present study, quadruplicate groups of juvenile Atlantic salmon (Salmo salar) were fed plant protein-based diets with increasing arginine inclusions (range $28.8-37.4 \mathrm{~g} / \mathrm{kg} \mathrm{DM}$ ) to investigate whether arginine supplementation affects growth and lipid accumulation through an elevated polyamine turnover. Dietary lysine was held at a constant concentration, just below the requirement. All other amino acids were balanced and equal in the diets. Arginine supplementation increased protein and fat accretion, without affecting the hepatosomatic or visceralsomatic indices. Dietary arginine correlated with putrescine in the liver $(R 0 \cdot 78, P=0 \cdot 01)$ and with ornithine in the muscle, liver and plasma $(P=0.0002,0.003$ and 0.0002, respectively). The mRNA of ornithine decarboxylase, the enzyme producing putrescine, was up-regulated in the white adipose tissue of fish fed the high-arginine inclusion compared with those fed the low-arginine diet. Concomitantly, spermidine/spermine-(N1)-acetyltransferase, the rate-limiting enzyme for polyamine turnover that consumes acetyl$\mathrm{CoA}$, showed an increased activity in the liver of fish fed the arginine-supplemented diets. In addition, lower acetyl-CoA concentrations were observed in the liver of fish fed the high-arginine diet, while ATP, which is used in the process of synthesising spermidine and spermine, did not show a similar trend. Gene expression of the rate-limiting enzyme for $\beta$-oxidation of long-chain fatty acids, carnitine palmitoyl transferase-1, was up-regulated in the liver of fish fed the high-arginine diet. Taken together, the data support that increased dietary arginine activates polyamine turnover and $\beta$-oxidation in the liver of juvenile Atlantic salmon and may act to improve the metabolic status of the fish.
\end{abstract}

Key words: Arginine: Atlantic salmon: Polyamines: Spermidine/spermine-(N1)-acetyltransferase

Inclusion of plant protein ingredients in commercial fish feed has rapidly increased over the last decade, with consequent changes in amino acid composition that possibly affect metabolic pathways, growth and deposition in fish ${ }^{(1-4)}$. Arginine and lysine are indispensable amino acids in fish, and antagonistic effects on uptake between the two amino acids have been reported in mammals and fish ${ }^{(5-7)}$. Traditional fishmeal diets have sufficient amounts of both amino acids, while plant protein-based diets often require supplementation, and optimum levels and ratios between the two amino acids, therefore, have to be investigated.

Besides the need for protein synthesis, arginine is essential for a range of metabolic pathways, such as the production of polyamines, urea, NO and creatine, and fish probably have arginine requirement beyond the maximum requirement for growth $^{(8)}$. Arginine is the precursor for ornithine, by the enzyme arginase, which again is the only precursor for the polyamines putrescine, spermidine and spermine. Ornithine decarboxylase (ODC), the rate-limiting enzyme of polyamine synthesis, converts ornithine to putrescine, which again can be converted to spermidine and spermine, a process consuming decarboxylated $S$-adenosylmethionine $(\mathrm{SAM})^{(9)}$, which is synthesised from methionine in an ATP-dependent process ${ }^{(10)}$. Polyamines are small organic molecules present in all eukaryotic cells ${ }^{(11)}$ that are positively charged at the physiological $\mathrm{pH}$, allowing them to bind to the DNA and RNA, affecting transcription and translation ${ }^{(9)}$. Through such interactions, polyamines are capable of modulating a range of cellular mechanisms that are essential for cell growth and differentiation as well as for mitochondrial function and integrity ${ }^{(8,12)}$.

Abbreviations: CPT-1, carnitine palmitoyl transferase-1; ODC, ornithine decarboxylase; SAM, S-adenosylmethionine; SAMdc, S-adenosylmethionine decarboxylase; SSAT, spermidine/spermine- $(N 1)$-acetyltransferase; WAT, white adipose tissue.

*Corresponding author: S. M. Andersen, fax +47559052 99, email san@nifes.no 
The enzyme spermidine/spermine-(N1)-acetyltransferase (SSAT) acetylates the polyamines, consuming acetyl-CoA, enabling them to be transported out of the cell or to be oxidised to a shorter polyamine. The turnover of polyamines then might deplete the acetyl-CoA pools in the cells and thus has the capacity to decrease malonyl-CoA concentration, releasing its inhibitory effect on carnitine palmitoyl transferase-1 (CPT-1), the rate-limiting enzyme in the oxidation of the long-chain fatty acids in the mitochondria ${ }^{(13)}$. Transgenic mice having an increased SSAT activity were characterised by increased putrescine and decreased spermine and spermidine pools and chronic oxidative stress, as well as being significantly leaner when compared with wild-type mice $^{(14,15)}$. Mice overexpressing ODC or decarboxylated $S$-adenosylmethionine decarboxylase (SAMdc), however, did not have altered polyamine metabolism ${ }^{(16)}$, highlighting the importance of SSAT regulation for polyamine metabolism.

L-Arginine supplementation is known to reduce adiposity in genetically diet-induced obese rats and obese humans with diabetes mellitus type- $2^{(17,18)}$ as well as to increase protein accretion in pig muscle ${ }^{(19,20)}$. Tan et al. ${ }^{(20,21)}$ showed that arginine stimulated lipogenesis in the muscle and lipolysis in the adipose tissue in pigs by differentially regulating the expression of genes in these tissues, which resulted in increased muscle mass and an improved metabolic profile. Arginine supplementation has also been shown to enhance fatty acid oxidation via the production of $\mathrm{NO}$, through an increased expression of lipolytic proteins ${ }^{(18)}$. The mechanisms underlying the lipid-reducing effect of L-arginine supplementation are complex, but seem to involve those in favour of fat loss and/or that reduce the adipocyte mass as well as stimulate mitochondrial biogenesis and brown adipose tissue development in rodent models. Growing evidence that arginine supplementation promotes the oxidation of long-chain fatty acids and glucose, concomitantly decreasing de novo synthesis of glucose and TAG, has been presented ${ }^{(8,17)}$. In humans, excess body fat is mainly stored as TAG in abdominal white adipose tissue (WAT), while Atlantic salmon store fat both in the viscera, liver, and in the white muscle ${ }^{(22,23)}$. Thus, arginine supplementation has the potential to improve the metabolic profile and health status of Atlantic salmon by promoting skeletal muscle growth and viscera mass reduction.

The aim of the present study was to assess whether arginine supplementation in a plant protein-based diet would affect the type of growth and polyamine metabolism and alter the energy status of juvenile Atlantic salmon.

\section{Materials and methods \\ Diets}

The diets contained a high inclusion of plant protein ingredients and a marine fat source. The four experimental diets were prepared to contain increasing concentrations of arginine, from diet A (low arginine) to diet D (high arginine). Lysine was supplemented at levels just below the expected requirement ${ }^{(2)}$ to avoid lysine interactions. Compositions of the diets are listed in Table 1 . All other amino acids remained
Table 1. Diet formulation and chemical analysis of the diets*

\begin{tabular}{|c|c|c|c|c|}
\hline Diets... & $A$ & $B$ & $\mathrm{C}$ & $\mathrm{D}$ \\
\hline \multicolumn{5}{|l|}{ Diet formulation } \\
\hline Fishmeal & 107 & 107 & 107 & 107 \\
\hline Plant proteins $†$ & 642 & 642 & 642 & 642 \\
\hline L-Arg & 0 & $3 \cdot 2$ & 6.4 & $9 \cdot 6$ \\
\hline Fish oil & 99 & 99 & 99 & 99 \\
\hline Premix/binder $\ddagger$ & $153 \cdot 2$ & $150 \cdot 2$ & $147 \cdot 2$ & $143 \cdot 2$ \\
\hline \multicolumn{5}{|l|}{ Chemical analysis } \\
\hline \multicolumn{5}{|l|}{ DM } \\
\hline Energy (MJ/kg) & $19 \cdot 8$ & $19 \cdot 6$ & $20 \cdot 0$ & $19 \cdot 6$ \\
\hline Protein & 510 & 510 & 530 & 520 \\
\hline Fat & 103 & 97 & 101 & 101 \\
\hline Water & 92 & 86 & 74 & 104 \\
\hline Ash & 80 & 80 & 82 & 79 \\
\hline \multicolumn{5}{|l|}{ Amino acids } \\
\hline Arg & $28 \cdot 8$ & 31.7 & $35 \cdot 0$ & $37 \cdot 4$ \\
\hline Met & $11 \cdot 7$ & 11.5 & $11 \cdot 4$ & $11 \cdot 2$ \\
\hline Cys & $6 \cdot 6$ & $6 \cdot 7$ & $6 \cdot 6$ & $6 \cdot 5$ \\
\hline Lys & $24 \cdot 6$ & $23 \cdot 9$ & 23.9 & $23 \cdot 3$ \\
\hline Thr & $17 \cdot 4$ & $17 \cdot 0$ & $17 \cdot 2$ & $16 \cdot 8$ \\
\hline Trp & $5 \cdot 0$ & $5 \cdot 0$ & $5 \cdot 0$ & 4.9 \\
\hline Ile & $20 \cdot 1$ & $20 \cdot 3$ & $20 \cdot 1$ & $19 \cdot 8$ \\
\hline Leu & $40 \cdot 0$ & 39.9 & $39 \cdot 8$ & $39 \cdot 2$ \\
\hline Val & $22 \cdot 2$ & $22 \cdot 1$ & $22 \cdot 0$ & $21 \cdot 6$ \\
\hline His & $11 \cdot 3$ & $10 \cdot 7$ & $10 \cdot 6$ & $11 \cdot 0$ \\
\hline Phe & $23 \cdot 7$ & 23.7 & $23 \cdot 7$ & $23 \cdot 4$ \\
\hline Gly & $20 \cdot 6$ & $20 \cdot 1$ & $20 \cdot 2$ & $19 \cdot 8$ \\
\hline Ser & $22 \cdot 4$ & $22 \cdot 0$ & $22 \cdot 2$ & 21.9 \\
\hline Ala & $23 \cdot 1$ & $22 \cdot 7$ & $22 \cdot 7$ & $22 \cdot 3$ \\
\hline Asp & $42 \cdot 3$ & $42 \cdot 0$ & $42 \cdot 2$ & 41.4 \\
\hline Glu & $92 \cdot 8$ & $93 \cdot 2$ & 93.0 & $92 \cdot 4$ \\
\hline Arg:Lys ratio & $1 \cdot 17$ & $1 \cdot 33$ & 1.46 & 1.61 \\
\hline
\end{tabular}

${ }^{*}$ All values are listed as $\mathrm{g} / \mathrm{kg}$ diet, unless stated otherwise.

†Plant protein blend: soya concentrate:wheat gluten:pea protein concentrate:maize

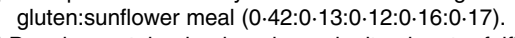

$\ddagger$ Premix contained minerals and vitamins to fulfil the requirement of Atlantic salmon $^{(39)}$.

constant among the diets (Table 1 ). The diets were extruded and pellet size was $1.5 \mathrm{~mm}$. All diets were produced by EWOS Innovation. Protein, fat and energy contents were equal in all the diets.

\section{Feeding trial}

The experiment complied with the guidelines of the Norwegian Regulation on Animal Experimentation and European Community Directive 86/609/EEC. The feeding trial was carried out in Dirdal, Norway, from December 2011 to February 2012. Each diet was randomly assigned to four replicate tanks, with each containing 140 fish with an initial weight of $5 \mathrm{~g}$. A total of sixteen glass fibre tanks $(0.6 \mathrm{~m} \times 0.6 \mathrm{~m})$ were used, with each being filled with 165 litres of fresh water. The fish were acclimatised in the experimental tanks for 2 weeks with a commercial diet before the commencement of the study. Bulk weights were measured at the commencement of the trial, every second week after switching to the experimental diets and at the end after 8 weeks with their respective diets. For the first 2 weeks, the fish were fed the experimental diets ad libitum, and later they were fed a restrictive diet, $95 \%$ of the requirement as set by the Norwegian feed tables. Continuous light was applied, and the fish were fed continuously using automatic feeders throughout the day and night 
(repeatedly fed for $0.33 \mathrm{~min}$ and then held for $7.25 \mathrm{~min}$ ). The mean water temperature throughout the experiment was $12 \cdot 7(\operatorname{sem} 1 \cdot 0)^{\circ} \mathrm{C}$.

\section{Sampling}

From each tank, pooled samples from ten fish were bulk weighed for total body weight, liver weight and gastrointestinal weight. Liver weight and gastrointestinal weight were used to calculate the hepatosomatic and visceralsomatic indices (percentage of body weight). Pooled samples of an additional ten fish from each tank were collected and frozen on ice for later chemical analysis. Samples of liver, WAT and muscle were sampled from at least three fish from each tank, flash frozen on liquid $\mathrm{N}_{2}$ and stored at $-80^{\circ} \mathrm{C}$ until analysis. Heparinised blood was drawn from the caudal vein of an additional ten fish and centrifuged and pooled plasma from each tank was stored at $-80^{\circ} \mathrm{C}$ until analysis.

\section{Chemical analyses}

Energy, fat and protein contents of the feeds were determined as described by Espe et al. ${ }^{(1)}$.

Total amino acid composition in the diets and whole fish was determined after hydrolysis for $22 \mathrm{~h}$ at $110^{\circ} \mathrm{C}$ in $6 \mathrm{M}-\mathrm{HCl}$ containing $3.125 \mathrm{~mm}$-Norvaline (internal standard) and $3 \mathrm{~mm}-$ dithiothreitol (to protect the sulphur amino acids against oxidation) and pre-column derivatised with AccQTag $^{\mathrm{TM}}$ at $55^{\circ} \mathrm{C}$ as described by Waters. The amino acids were separated on an ultra-high performance liquid chromatrography (UPLC) system (Waters Aquity UPLC BEH C18 column with an internal diameter of $1.7 \mu \mathrm{m}$ at a flow rate of $0.7 \mathrm{ml} / \mathrm{min}$ using the gradient offered by the supplier). The concentration of the amino acids was calculated using external standards supplied by Sigma. Tryptophan was determined after basic hydrolysis with $\mathrm{Ba}(\mathrm{OH})_{2}$ as described by Liaset et al. ${ }^{(24)}$. Total arginine gain and lysine gain were then calculated as the difference in each amino acid, in g, between the start and the end of the trial. Free amino acids were determined in the pooled samples of plasma, liver and muscle on a Biochrom 20 plus amino acid bioanalyzer (Amersham Pharmacia Biotech) using post-column derivatisation with ninhydrin as described by Espe et al. ${ }^{(1)}$.

\section{Metabolites}

Polyamines were analysed using HPLC and calculated with Empower (Waters). Extraction was done from $1 \mathrm{~g}$ of tissue in a total of $5 \mathrm{ml}$ of $0.4 \mathrm{M}$-perchloric acid with an internal standard as described by Liaset \& Espe ${ }^{(25)}$. SAM and $S$-adenosylhomocysteine (SAH) were determined using reverse-phase HPLC after deproteinisation in $0.4 \mathrm{M}$-perchloric acid as described by Wang et $a l .{ }^{(26)}$. The concentrations of SAM and SAH were quantified using standards of the respective metabolites (Sigma-Aldrich). Liver samples were deproteinised in perchloric acid using a deproteinising sample preparation kit, according to the manufacturer's instructions. ATP and acetyl-CoA were measured in deproteinised liver samples using an ATP fluorimetric assay kit and a PicoProbe Acetyl-CoA Assay kit, respectively, following the manufacturer's protocol (all kits from BioVision).

\section{Spermidine/spermine-(N1)-acetyltransferase abundance and activity}

Western blotting was used to investigate the abundance of SSAT in the liver. Collection samples from each tank were homogenised in four volumes of $10 \mathrm{~mm}$-Tris buffer ( $\mathrm{pH} 7 \cdot 6$ ) with $1 \mathrm{~mm}$-EDTA and $0.25 \mathrm{M}$-sucrose and spun at $8000 \mathrm{~g}$ for $40 \mathrm{~min}$ at $4^{\circ} \mathrm{C}$, and the collected supernatant was stored at $-80^{\circ} \mathrm{C}$ until used. Proteins were separated on SDS gels (12\%), Western blotted on a polyvinylidene difluoride (PVDF) membrane and detected by Chemiluminescence Image Capture as described by Espe \& Holen ${ }^{(27)}$. The gels were simultaneously stained for SSAT (anti-SAT1, ab54047; Abcam) and $\beta$-actin (no. 4967; BioNordica/Cell Signaling), and the relative quantities of SSAT compared with $\beta$-actin were calculated. The values obtained in the fish fed diet A were set to 100, and those of fish fed the other diets were calculated relative to this. The enzyme activity of SSAT was determined using Ellman's reagent, measuring the amount of the product COA-SH produced per min by SSAT as described by Lin et al. ${ }^{(28)}$.

\section{Gene expression}

RNA and complementary DNA were obtained from three fish from each tank, and the means obtained for each tank were used to calculate the relative values. RNA was extracted from the liver samples using the EZ1 BioRobot and the RNA Universal Tissue Kit (Qiagen), according to the manufacturer's instructions. RNA extraction from the WAT was carried out manually with TRIzol. All RNA samples were DNase treated to remove any contaminating DNA. Total RNA concentration was determined at $260 \mathrm{~nm}$ with the NanoDrop ND-1000 UV-Vis spectrophotometer (NanoDrop Technologies), and quality was assessed with the Agilent 2100 Bioanalyzer (Agilent Technologies). For the liver and WAT samples, the RNA integrity numbers (RIN) were $9 \cdot 87$ and 6.48 (SEM $0 \cdot 10$ and 0.15 ), respectively. A two-step quantitative PCR was run as described by Torstensen et al. ${ }^{(29)}$. Briefly, $500 \mathrm{ng}$ of RNA were reverse-transcribed into complementary DNA, with duplicates of each sample, using a TaqMan ${ }^{\circledR}$ Gold RT-PCR Kit (Applied Biosystems), with the following protocol: $25^{\circ} \mathrm{C}$ for $10 \mathrm{~min} ; 60^{\circ} \mathrm{C}$ for $48 \mathrm{~min} ; 95^{\circ} \mathrm{C}$ for $5 \mathrm{~min}$, and stored at $-20^{\circ} \mathrm{C}$. Gene expression was quantified with quantitative PCR on the Lightcycler 480 (Roche Applied Sciences), on the following programme: $95^{\circ} \mathrm{C}$ for $5 \mathrm{~min}$; forty-five cycles of $95^{\circ} \mathrm{C}$ for $10 \mathrm{~s} ; 60^{\circ} \mathrm{C}$ for $20 \mathrm{~s} ; 72^{\circ} \mathrm{C}$ for $30 \mathrm{~s}$, followed by a melt curve analysis. The quantitative PCR primers were synthesised by Invitrogen after a BLAST search, which are listed in Table 2. To confirm the specificity of the primers, Sanger DNA sequencing (Applied Biosystems 3730XL Analyzer) was performed on purified PCR products after preparation using Big Dye v.3.1, according to the manufacturer's instructions. Relative quantities were calculated against the reference genes $\beta$-actin and elongation factor $1 \mathrm{Ab}$, verified in Atlantic salmon ${ }^{(30)}$. 
Table 2. Primer sequences, accession numbers and sizes of the products

\begin{tabular}{llcll}
\hline Genes & Accession no. & Size $(\mathrm{bp})$ & \multicolumn{1}{c}{ Forward primer $\left(5^{\prime}-3^{\prime}\right)$} & \multicolumn{1}{c}{ Reverse primer $\left(5^{\prime}-3^{\prime}\right)$} \\
\hline SSAT & NM_002970.2 & 155 & TCGTGGCGGAAGTCCCCAGT & GCCGATGCCAAACCCCCTGT \\
ODC & BT045263.1 & 79 & CAGACTGGCAACTCTGCAGGC & GCAGCCAAGGCGGTTCACCA \\
SAMdc & NM_001165344.1 & 103 & CTGTCCAGCCTTGCCCCGTG & GGGCCCTGGACTAGTGGGCA \\
CPT-1 & AM230810 & 161 & GAGAGAGCTGCGACTGAAAC & GACAGCACCTCTTTGAGGAA \\
EF1Ab & BG933853 & 59 & TGCCCCTCCAGGATGTCTAC & CACGGCCCACAGGTACTG \\
$\beta$-Actin & BG933897 & 92 & CCAAAGCCAACAGGGAGAA & AGGGACAACACTGCCTGGAT \\
\hline
\end{tabular}

$S S A T$, spermidine/spermine-(N1)-acetyltransferase; ODC, ornithine decarboxylase; SAMdC, S-adenosylmethionine decarboxylase; CPT-1, carnitine palmitoyl transferase-1; EF1Ab, elongation factor $1 \mathrm{Ab}$.

\section{Statistical analyses}

All statistical calculations were performed in Statistica 11 (StatSoft, Inc.) using a one-way ANOVA, followed by Tukey's post hoc test or, when applicable, an unequal $N$ post hoc test. Average tank values were used as the statistical unit. Levene's test was applied to test for homogeneity in variances between the groups. $P$ values less than 0.05 were accepted as statistically different. Regression analyses were performed in Statistica 11, determining bivariate correlations, with arginine concentration in the diet as a continuous variable.

\section{Results}

\section{Growth}

The fish fed the highest arginine diet, diet D, grew better and displayed a higher weight gain than the fish fed diet $\mathrm{B}$ (Table 3). Diet D also resulted in higher protein gain and fat gain compared with diet $\mathrm{B}$. However, neither of these values correlated with arginine concentration in the diets, as the regression analysis gave $R$ values of $0.23,0.18$ and 0.22 for growth, protein gain and fat gain, respectively. The hepatosomatic and visceralsomatic indices were similar between the dietary groups. Overall, all the parameters measured, including weight gain, protein and fat deposition and specific growth rate, were lower in the fish fed diet $\mathrm{B}$ than in those fed diet A, while the regression analysis showed a correlation between these parameters and increasing dietary arginine in the fish fed diet B to those fed diet D only.

\section{Polyamines}

In the liver, putrescine concentrations increased with increasing arginine concentrations in the feed $(P=0 \cdot 01$; Table 4$)$, correlating with arginine concentration in the diets $\left(\begin{array}{ll}R & 0.69\end{array}\right)$. Spermidine and spermine concentrations in the liver remained unchanged between the dietary groups. In the WAT, there were no observed differences in either of the polyamines. The fish fed diet D, containing the highest dose of arginine, had higher concentrations of spermine in the muscle compared with the fish fed diet $\mathrm{B}$, while putrescine and spermidine concentrations were unaffected. The products of SSAT, acetylated spermidine and acetylated spermine, were not detected by the method. Other polyamines, such as cadaverine, tyramine and phenylethylamine, were also measured by the method, but either they were found at levels below the detection limit or there were no differences observed.

\section{Gene expression and spermidine/spermine-(N1)- acetyltransferase regulation}

Gene expression was analysed in the fish fed diets B and D, as these two groups exhibited the greatest growth difference, and as the diets were examples of a low-arginine diet (B) and a high-arginine diet (D); the results are displayed in Fig. 1. In the WAT, $O D C$ expression was up-regulated in the salmon fed diet D compared with those fed diet $\mathrm{B}(P=0 \cdot 01)$. Signs of a similar up-regulation were also found in the liver, though not significant $(P=0 \cdot 13) . C P T-1$, however, was

Table 3. Growth, protein gain and lipid gain, as well as the mean total gain of the amino acids arginine (Arg) and lysine (Lys) in juvenile salmon fed the experimental diets for 8 weeks

(Mean values with their standard errors, $n 4$ )

\begin{tabular}{|c|c|c|c|c|c|c|c|c|c|}
\hline \multirow[t]{2}{*}{ Diets... } & \multicolumn{2}{|c|}{ A } & \multicolumn{2}{|c|}{ B } & \multicolumn{2}{|c|}{ C } & \multicolumn{2}{|c|}{$\mathrm{D}$} & \multirow[b]{2}{*}{$P^{\star}$} \\
\hline & Mean & SE & Mean & SE & Mean & SE & Mean & SE & \\
\hline IBW (g) & 5.40 & 0.03 & 5.06 & 0.08 & $5 \cdot 15$ & 0.14 & $5 \cdot 28$ & 0.07 & 0.07 \\
\hline EBW (g) & $23 \cdot 02^{a, b}$ & 0.79 & $19 \cdot 76^{a}$ & 0.70 & $21 \cdot 78^{a, b}$ & $1 \cdot 12$ & $23 \cdot 81^{\mathrm{b}}$ & 0.64 & 0.02 \\
\hline Weight gain (g) & $17 \cdot 62^{a, b}$ & 0.80 & $14 \cdot 70^{\mathrm{a}}$ & 0.62 & $16 \cdot 63^{a, b}$ & 1.00 & $18 \cdot 53^{b}$ & 0.61 & 0.02 \\
\hline Protein gain (g/fish) & $3 \cdot 23^{a, b}$ & 0.16 & $2 \cdot 62^{a}$ & 0.11 & $2 \cdot 98^{a, b}$ & $0 \cdot 16$ & $3 \cdot 28^{\mathrm{b}}$ & 0.13 & 0.04 \\
\hline Fat gain (g/fish) & $1.52^{\mathrm{a}, \mathrm{b}}$ & 0.09 & $1.23^{\mathrm{a}}$ & 0.05 & $1 \cdot 39^{a, b}$ & 0.11 & $1.60^{\mathrm{b}}$ & 0.04 & 0.02 \\
\hline $\mathrm{HSI}$ & 1.48 & 0.08 & 1.49 & $0 \cdot 10$ & 1.42 & 0.04 & 1.50 & 0.03 & 0.87 \\
\hline VSI & $8 \cdot 16$ & 0.07 & 7.72 & 0.09 & 8.08 & 0.26 & 8.34 & 0.28 & 0.48 \\
\hline Arg gain (mg/fish) & $6 \cdot 96^{a, b}$ & 0.27 & $5.97^{\mathrm{a}}$ & 0.21 & $6 \cdot 61^{a, b}$ & 0.33 & $7 \cdot 13^{\mathrm{b}}$ & 0.22 & 0.05 \\
\hline Lys gain (mg/fish) & $2 \cdot 29$ & 0.13 & 1.90 & 0.07 & $2 \cdot 16$ & 0.14 & $2 \cdot 34$ & 0.07 & 0.07 \\
\hline
\end{tabular}

IBW, initial body weight; EBW, end body weight; HSI, hepatosomatic index; VSI, visceralsomatic index.

a,b Mean values with unlike superscript letters were significantly different $(P<0.05)$.

*One-way ANOVA with Tukey's post hoc test was used. 
Table 4. Polyamine concentrations in the liver, white adipose tissue (WAT) and muscle ( $\mathrm{mg} / \mathrm{kg}$ ) of juvenile salmon

(Mean values with their standard errors, $n 4$ )

\begin{tabular}{|c|c|c|c|c|c|c|c|c|c|}
\hline \multirow{2}{*}{ Diets... } & \multicolumn{2}{|c|}{ A } & \multicolumn{2}{|c|}{ B } & \multicolumn{2}{|c|}{$C$} & \multicolumn{2}{|c|}{ D } & \multirow[b]{2}{*}{$P^{*}$} \\
\hline & Mean & SE & Mean & SE & Mean & SE & Mean & $\mathrm{SE}$ & \\
\hline \multicolumn{10}{|l|}{ Liver } \\
\hline Putrescine & $133.4^{\mathrm{a}}$ & 6.9 & $138.9^{\mathrm{a}}$ & $5 \cdot 2$ & $145 \cdot 3^{\mathrm{a}, \mathrm{b}}$ & $2 \cdot 3$ & $162 \cdot 3^{\mathrm{b}}$ & 4.0 & 0.01 \\
\hline Spermidine & 148.7 & 4.5 & 152.9 & $3 \cdot 2$ & $146 \cdot 4$ & 1.6 & $146 \cdot 0$ & 3.4 & 0.50 \\
\hline Spermine & $54 \cdot 7$ & 1.2 & 60.5 & 1.9 & 58.2 & 1.4 & $59 \cdot 6$ & 1.6 & 0.14 \\
\hline \multicolumn{10}{|l|}{ WAT } \\
\hline Putrescine & $21 \cdot 3$ & $3 \cdot 1$ & $21 \cdot 3$ & $3 \cdot 3$ & $18 \cdot 2$ & $2 \cdot 6$ & 19.5 & $2 \cdot 6$ & 0.87 \\
\hline Spermidine & $24 \cdot 3$ & 3.8 & 21.9 & $2 \cdot 8$ & $18 \cdot 3$ & $2 \cdot 3$ & $20 \cdot 1$ & $2 \cdot 4$ & 0.47 \\
\hline Spermine & 6.8 & 1.2 & $6 \cdot 9$ & 0.6 & 5.5 & 0.5 & $5 \cdot 8$ & 0.9 & 0.62 \\
\hline \multicolumn{10}{|l|}{ Muscle } \\
\hline Putrescine & $8 \cdot 3$ & 0.2 & $7 \cdot 8$ & 0.4 & 8.2 & 0.3 & $9 \cdot 3$ & 0.6 & 0.14 \\
\hline Spermidine & $15 \cdot 7$ & $0 . \overline{5}$ & 13.7 & 0.2 & 14.4 & 0.7 & $15 \cdot 0$ & $1 \cdot 1$ & 0.36 \\
\hline Spermine & $34 \cdot 0^{a, b}$ & 0.4 & $31 \cdot 7^{a}$ & 1.1 & $32 \cdot 8^{a, b}$ & 0.4 & $36 \cdot 6^{b}$ & 1.7 & 0.04 \\
\hline
\end{tabular}

a,b Mean values with unlike superscript letters were significantly different $(P<0.05)$.

${ }^{*} P$ values are listed as the lowest observed $P$ value between any of the four diets. One-way ANOVA with Tukey's post hoc test was used to calculate the significance.

significantly up-regulated in the liver of fish fed diet $\mathrm{D}$ compared with those fed diet $\mathrm{B}$, while expression in the WAT was unaffected. $S A M d c$ expression remained unchanged in both the WAT and liver of the two dietary groups. SSAT, the enzyme acetylating spermine and spermidine by converting them back into shorter polyamines, did not appear to be regulated at the genetic level, in either the WAT or the liver, as quantitative PCR results showed no significant changes. Western blotting gave a bright clear band of SSAT at $28 \mathrm{kDa}$ and a band of $\beta$-actin at $45 \mathrm{kDa}$. These results showed no differences in SSAT abundance in the liver between the dietary groups (Fig. 2(A)). The activity of SSAT, on the other hand, as measured by the amount of CoA-SH produced, was higher in the liver of fish fed diets $\mathrm{B}$ and $\mathrm{C}$ compared with those fed diet A (low arginine; Fig. 2(B)), and SSAT activity correlated with

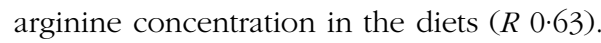

(A)

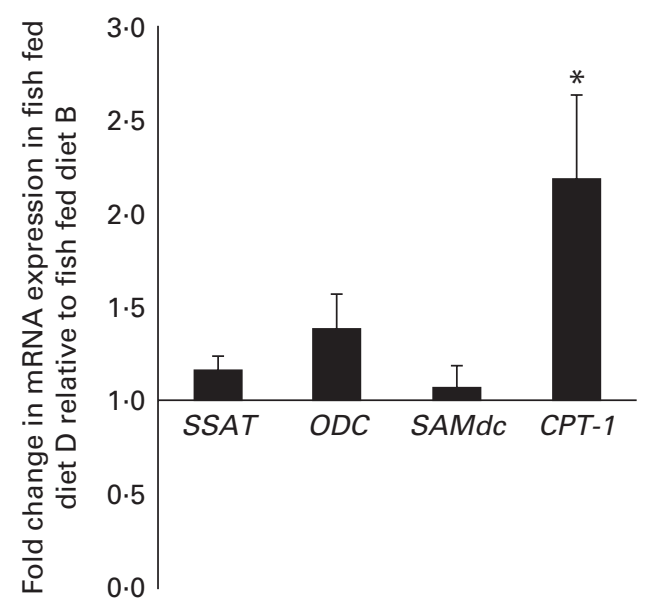

\section{Amino acids and metabolites}

The concentrations of free arginine, lysine and methionine, as well as those of the metabolites of arginine in the muscle, liver and plasma, are listed in Table 5. In the muscle and plasma, increasing arginine in the diets resulted in increasing arginine concentrations in the tissues. In the liver, however, there was no difference in arginine between the dietary groups. Neither lysine nor methionine was altered in any of the tissues examined. The arginine:lysine ratio was affected in the muscle and plasma, with significant differences being observed between fish fed the lowest concentration of arginine (diet A) and those fed the highest concentration of arginine (diet D). In the liver, however, no changes were observed in the ratios of arginine:lysine. Ornithine concentrations in the liver, muscle and plasma increased from diet A through diet D

(B)

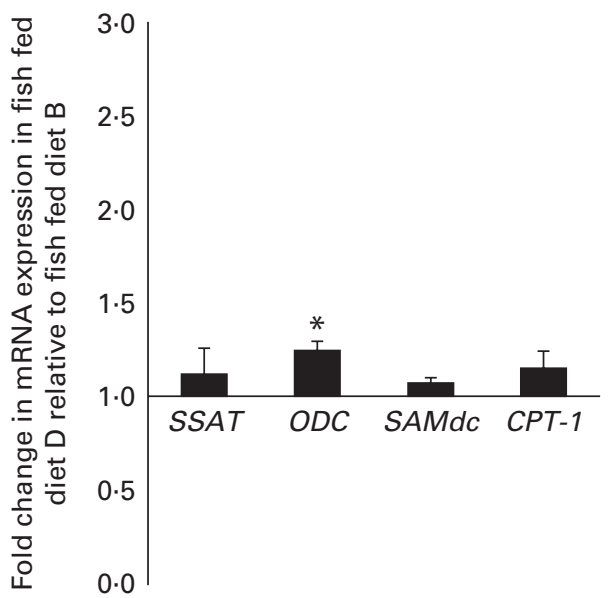

Fig. 1. Fold change in gene expression in the (A) liver and (B) white adipose tissue (WAT) of group D (high-arginine (Arg) diet) relative to group $B$ (low-Arg diet). Values are means $(n 4)$, with their standard errors represented by vertical bars. * Mean values with unlike letters were significantly different $(P<0.05$; one-way ANOVA with Tukey's post hoc test). SSAT, spermidine/spermine-(N1)-acetyltransferase; ODC, ornithine decarboxylase; SAMdc, S-adenosylmethionine decarboxylase; CPT-1, carnitine palmitoyl transferase-1. 
(A)

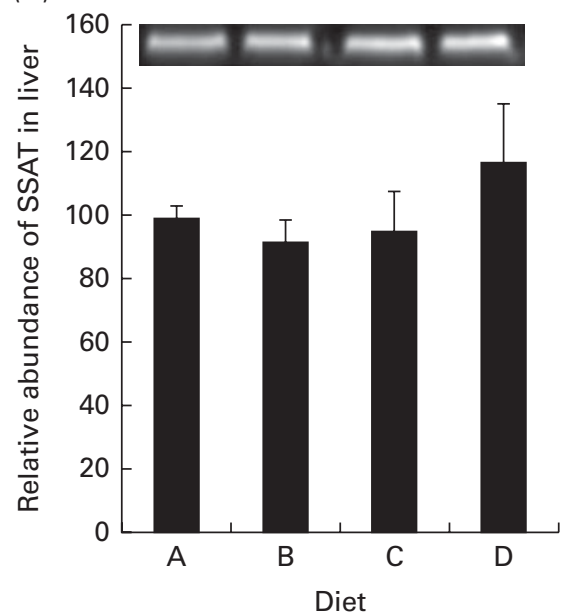

(B)

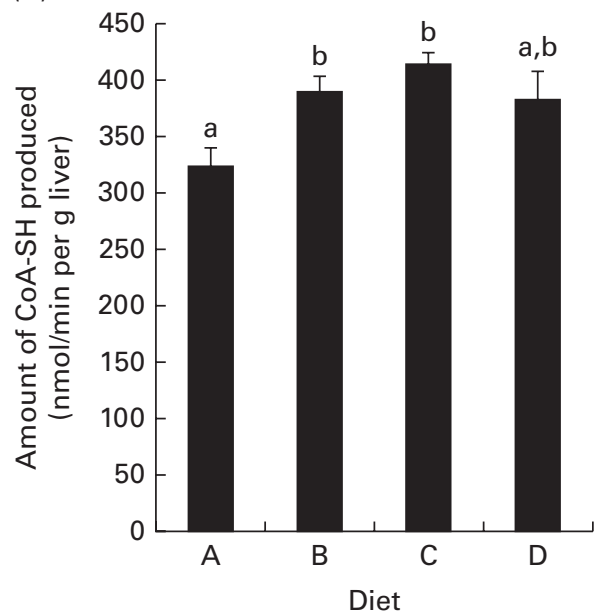

Fig. 2. Spermidine/spermine-(N1)-acetyltransferase (SSAT) abundance and activity in the liver. (A) Protein abundance of SSAT in the liver relative to the abundance of $\beta$-actin, with an inset of Western blotting bands of SSAT abundance. Diet A is set to $100, P=0.45$. (B) SSAT activity in homogenised samples collected from the liver, $P=0.004 ; n 4 .{ }^{\text {a,b }}$ Mean values with unlike letters were significantly different $(P<0.05$; one-way ANOVA with Tukey's post hoc test).

and correlated with arginine in the feed $(R 0.73,0.94$ and 0.91 and $\operatorname{Arg}=2 \cdot 0+0 \cdot 05 \times$ Orn, $2 \cdot 3+0.08 \times$ Orn and $2 \cdot 3+$ $0.004 \times$ Orn, respectively), indicating high arginase activity. Urea, which is released when arginine is converted to ornithine, was not affected in the liver, while its concentrations increased in the muscle and plasma with increasing arginine concentrations in the diets, thus indicating that urea produced in the liver is quickly released into the blood stream. Changes in $\mathrm{NH}_{3}$ were also observed in the muscle and liver, with no differences being observed in the plasma samples. Citrulline, another metabolite of arginine, was only detected in the plasma, with no effect from the diets being observed. Overall, the liver appears to be less affected by the changing arginine inclusion in the diet, which might

Table 5. Selected free amino acids and metabolites in the muscle, liver and plasma samples of the fish fed diets $A$ to $D^{*}$ (Mean values with their standard errors, $n 4$ )

\begin{tabular}{|c|c|c|c|c|c|c|c|c|c|}
\hline \multirow{2}{*}{ Diets... } & \multicolumn{2}{|c|}{ A } & \multicolumn{2}{|c|}{$\mathrm{B}$} & \multicolumn{2}{|c|}{$C$} & \multicolumn{2}{|c|}{$\mathrm{D}$} & \multirow[b]{2}{*}{$P \dagger$} \\
\hline & Mean & SE & Mean & SE & Mean & SE & Mean & SE & \\
\hline \multicolumn{10}{|l|}{ Muscle } \\
\hline Arg & $16 \cdot 7^{a}$ & 1.6 & $24 \cdot 5^{a, b}$ & 0.9 & $30 \cdot 5^{b}$ & $4 \cdot 3$ & $34 \cdot 6^{\mathrm{b}}$ & 2.6 & 0.003 \\
\hline Lys & $10 \cdot 3$ & $1 \cdot 3$ & 8.2 & 1.5 & $12 \cdot 6$ & 1.4 & $7 \cdot 4$ & $1 \cdot 0$ & 0.07 \\
\hline Met & $11 \cdot 0$ & 0.5 & $9 \cdot 8$ & 0.6 & $11 \cdot 6$ & 0.8 & $9 \cdot 6$ & 0.6 & 0.15 \\
\hline Arg:Lys ratio & $1 \cdot 6^{a}$ & 0.1 & $3 \cdot 3^{a, b}$ & 0.6 & $2 \cdot 5^{\mathrm{a}}$ & 0.4 & $5 \cdot 1^{b}$ & 1.0 & 0.01 \\
\hline Urea & $250 \cdot 9^{a}$ & 13.5 & $260 \cdot 1^{a, b}$ & $15 \cdot 8$ & $281 \cdot 5^{a, b}$ & $11 \cdot 1$ & $319 \cdot 0^{b}$ & $17 \cdot 3$ & 0.03 \\
\hline Orn & $8 \cdot 0^{a}$ & 0.3 & $11 \cdot 3^{\mathrm{b}}$ & 0.9 & $14 \cdot 0^{\mathrm{b}}$ & 0.8 & $17 \cdot 7^{\mathrm{C}}$ & 0.8 & 0.0002 \\
\hline $\mathrm{NH}_{3}$ & $410 \cdot 2^{a}$ & $5 \cdot 4$ & $433 \cdot 4^{b}$ & 3.4 & $423 \cdot 7^{a, b}$ & 4.7 & $417 \cdot 0^{a, b}$ & $3 \cdot 3$ & 0.01 \\
\hline \multicolumn{10}{|l|}{ Liver } \\
\hline Arg & $67 \cdot 2$ & 8.5 & $68 \cdot 3$ & $6 \cdot 3$ & $91 \cdot 1$ & $17 \cdot 0$ & $70 \cdot 3$ & $9 \cdot 3$ & 0.93 \\
\hline Lys & 104.9 & $5 \cdot 2$ & $102 \cdot 6$ & $6 \cdot 0$ & $105 \cdot 5$ & $2 \cdot 2$ & $102 \cdot 3$ & $8 \cdot 2$ & 0.99 \\
\hline Met & $37 \cdot 5$ & $2 \cdot 2$ & 33.9 & 2.9 & 45.5 & 4.9 & 35.5 & $3 \cdot 2$ & 0.40 \\
\hline Arg:Lys ratio & 0.6 & 0.06 & 0.7 & 0.02 & 0.7 & 0.03 & 0.7 & 0.04 & 0.69 \\
\hline Urea & 1090 & $87 \cdot 6$ & 967 & 93.0 & 1169 & $80 \cdot 2$ & 1189 & 91.6 & 0.33 \\
\hline Orn & $21 \cdot 6^{a}$ & 0.8 & $26 \cdot 0^{a, b}$ & 0.6 & $31 \cdot 7^{b}$ & 2.5 & $29 \cdot 9^{b}$ & 1.9 & 0.003 \\
\hline $\mathrm{NH}_{3}$ & $323^{a}$ & $5 \cdot 4$ & $331^{a, b}$ & 3.4 & $344 \cdot 1^{b}$ & 5.4 & $326 \cdot 5^{a, b}$ & $4 \cdot 7$ & 0.04 \\
\hline \multicolumn{10}{|l|}{ Plasma } \\
\hline Arg & $15 \cdot 1^{\mathrm{a}}$ & 0.7 & $20 \cdot 0^{\mathrm{b}}$ & 0.6 & $20 \cdot 1^{b}$ & 0.7 & $25 \cdot 6^{c}$ & $1 \cdot 3$ & 0.0002 \\
\hline Lys & $16 \cdot 9$ & $1 \cdot 0$ & $18 \cdot 1$ & $1 \cdot 0$ & $18 \cdot 2$ & 1.6 & 21.4 & $1 \cdot 1$ & 0.11 \\
\hline Met & $19 \cdot 6$ & 1.5 & $19 \cdot 7$ & 1.9 & $17 \cdot 9$ & $1 \cdot 2$ & 22.9 & $2 \cdot 4$ & 0.26 \\
\hline Arg:Lys ratio & $0.9^{a}$ & 0.01 & $1 \cdot 1^{a, b}$ & 0.02 & $1 \cdot 1^{a, b}$ & 0.1 & $1 \cdot 2^{b}$ & 0.1 & 0.04 \\
\hline Urea & $84 \cdot 3$ & $4 \cdot 8$ & 85.4 & $3 \cdot 7$ & $100 \cdot 2$ & $8 \cdot 3$ & 105.5 & 0.7 & 0.06 \\
\hline Orn & $1 \cdot 6^{a}$ & 0.1 & $2 \cdot 3^{b}$ & 0.1 & $2 \cdot 6^{\mathrm{b}}$ & 0.2 & $3 \cdot 3^{c}$ & 0.3 & 0.0002 \\
\hline $\mathrm{NH}_{3}$ & 79.5 & $8 \cdot 8$ & $86 \cdot 0$ & $5 \cdot 4$ & $98 \cdot 1$ & $10 \cdot 1$ & $92 \cdot 4$ & $15 \cdot 1$ & 0.52 \\
\hline Citrulline & $2 \cdot 0$ & 0.2 & 1.6 & 0.2 & 1.5 & 0.2 & $1 \cdot 8$ & 0.4 & 0.42 \\
\hline
\end{tabular}

a,b,c Mean values with unlike superscript letters were significantly different $(P<0.05)$.

${ }^{*}$ All data are given as $\mu \mathrm{mol} / 100 \mathrm{~g}$ tissue ( $100 \mathrm{ml}$ plasma).

† $P$ values are listed as the lowest observed $P$ value between any of the four diets. One-way ANOVA was performed with Tukey's post hoc test or an unequal $N$ test when applicable. 
indicate higher metabolic capacity or need for arginine. These differences also highlight the importance of investigating more than one tissue when looking at amino acids and their metabolites. Arginine gain and lysine gain were calculated from the analysis of total amino acids in the pooled whole fish samples. No significant differences were observed in lysine gain $(P=0.07)$, while arginine gain was highest in the fish fed diet $\mathrm{D}$, which was significantly higher than that in the fish fed diet B $(P=0 \cdot 046$; Table 3$)$.

\section{Effect on energy status}

ATP concentrations were lower in the liver of fish fed diet B compared with those fed all the other diets (Fig. 3(B)), while there was no difference among diets $\mathrm{A}, \mathrm{C}$ and D. Acetyl-CoA concentrations were not different between the experimental groups, though there was a trend in decreasing acetyl-CoA levels from the fish fed diet A to those fed diet D $(P=0.09$; Fig. 3(A)). SAM concentrations appeared to decrease in the fish fed diets $C$ and $D$ compared with those fed diets A and B, while SAH levels were slightly higher in the fish fed diet $\mathrm{C}$ than in those fed diets $\mathrm{A}$ and $\mathrm{B}$ (Fig. 3(C) and (D)), though neither of these values reached significance.

\section{Discussion}

Arginine supplementation has been reported to enhance muscle mass in several species ${ }^{(17,20)}$, and Yao et al. ${ }^{(19)}$ have found that arginine activates mammalian target of rapamycin signalling in pig muscle, favouring protein synthesis and growth. This supports the present findings that protein gain was enhanced in the fish fed diet D, as this high-arginine diet resulted in the highest weight and protein gain. Diet D also resulted in the highest fat gain, which differs from that observed in studies carried out in mammals, demonstrating a loss in visceral mass after arginine supplementation ${ }^{(17,18,20,31)}$. Tan et $a l .{ }^{(20)}$ showed that arginine supplementation differentially regulated lipid metabolic genes in the muscle and adipose tissue and that intramuscular fat content, as well as the weight of the muscle and brown adipose tissue, was increased $^{(17)}$ after arginine supplementation. However, as the concurrent loss of visceral mass exceeded the gain of
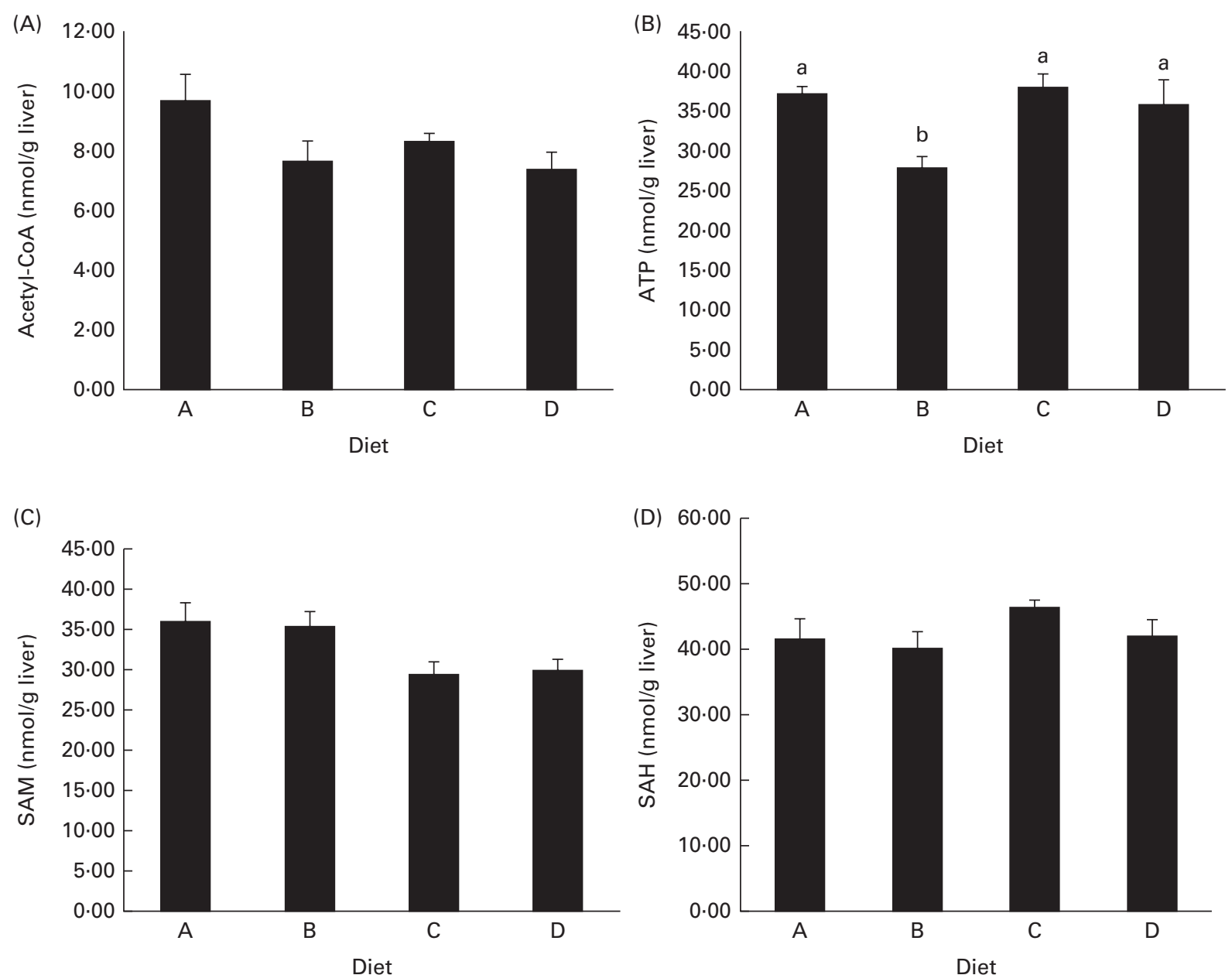

Fig. 3. Concentrations of (A) acetyl-CoA, $P=0.09$, (B) ATP, $P=0.02$, (C) $S$-adenosylmethionine (SAM), $P=0.08$, and (D) $S$-adenosylhomocysteine (SAH), $P=0.27$, in deproteinised liver samples. $P$ values are given as the lowest observed value between any of the four diets. Values are means (nmol/g tissue), with their standard errors represented by vertical bars $(n 4)$. ${ }^{a, b}$ Mean values with unlike letters were significantly different $(P<0.05$; one-way ANOVA with Tukey's post hoc test). 
muscle and brown adipose tissue mass, an overall weight loss was observed. In the present study, juvenile salmon, which are in a rapid growing life stage with minimal initial visceral mass, were used. The observed increased deposition of both fat and protein in the muscle therefore probably exceeds the possible lipolytic effect on the visceral mass by arginine, explaining the increased body weight, protein gain and fat gain observed in the highest-arginine diet. Still, weight gain, protein gain or fat gain did not correlate with arginine concentration in the diets, leading to the question whether there is a true arginine effect on growth. To the best of our knowledge, all reports on the effect of arginine on muscle and fat gain have been based on adult animals. With this in mind, it will be interesting to study arginine supplementation in growing/ adult Atlantic salmon to assess whether arginine would have a whole-body lipid-reducing effect. The hepatosomatic and visceralsomatic indices remained unchanged between the dietary groups, indicating that the higher growth from diet $\mathrm{D}$ is equally distributed among tissues, possibly showing a whole-body growth-promoting effect of arginine supplementation. As the diets used in the present study were all low in fat and energy content compared with commercial diets fed to juvenile salmon, it is possible that arginine supplementation enabled the fish to utilise the limited energy more efficiently. However, future studies are required to investigate this. Surprisingly, while diet D (high arginine) resulted in the highest weight gain, diet A (low arginine) appeared to yield higher growth than diets $\mathrm{B}$ and $\mathrm{C}$, though not significant. This was a pattern also observed for other parameters, such as protein gain and fat gain, some polyamine measurements and SSAT abundance in the liver. This might be due to the limited inhibition of lysine uptake by arginine in the salmon fed diet A (low arginine), thereby increasing the uptake of the already limited lysine in the diet ${ }^{(32)}$. Some of the lower values observed for the salmon fed diet B might be explained by the slightly lower initial body weight compared with that observed for the other experimental groups $(P=0.07)$. Due to this non-linear pattern in growth and deposition data, the groups fed diets $\mathrm{B}$ and $\mathrm{D}$ were chosen for gene expression analysis, as they exhibited the greatest difference in growth performance, and as the diets that they consumed represented those with adequate and surplus arginine concentrations.

Regulation of ODC is known to appear solely at the level of ODC protein abundance, and not due to its activity ${ }^{(9)}$, and we did indeed observe an up-regulation of mRNA expression for $O D C$ in the WAT of the group receiving the highest arginine inclusion in the diet (Fig. 1(B)), indicating more arginine being used towards polyamine synthesis. Surprisingly, no differences in the concentrations of either of the polyamines were observed in the WAT. Ornithine was observed at increasing concentrations in the liver, muscle and plasma, correlating with increasing arginine inclusions in the diets $(R 0.71,0.94$ and 0.91 , respectively), again indicating more arginine being used towards polyamine synthesis. Arginine supplementation did not affect the mRNA expression of SSAT in the WAT or liver, but as the regulation of SSAT occurs at several levels including splicing, translation, activity and degradation ${ }^{(9)}$, it is likely that arginine affects SSAT at another level rather than during gene expression in the liver and WAT of salmon. This is supported by the present findings showing the regulation of the protein activity of SSAT in the liver (Fig. 2(B)). SSAT activity increased with the supplemented arginine, before appearing to reach a plateau. Protein abundance, as investigated with Western blotting, however, showed no difference between the dietary groups, though it displayed a tendency to increase in the fish fed the high-arginine diet. Taken together, these findings indicate that arginine regulates SSAT in the liver of salmon mainly at the post-transcriptional level.

Arginine in the diets clearly correlated with ornithine and putrescine in the liver, and taken together with the increased SSAT activity observed after arginine supplementation, this indicates increased production and turnover of polyamines. Increased synthesis of polyamines leads to higher SSAT activity and decreased degradation of the enzyme ${ }^{(33)}$, which increases the polyamine turnover and explains the steady pool of spermine and spermidine observed in the liver. In theory, as SSAT consumes acetyl-CoA, the cellular levels of acetyl-CoA decrease and the following decrease in malonylCoA levels will decrease fatty acid synthesis ${ }^{(33)}$. Acetyl-CoA levels did show a tendency to decrease in the liver with increasing arginine supplementation, though not reaching significance (Fig. 3(A); $P=0 \cdot 09$ ). Jell et $a l{ }^{(34)}$ also found no change in acetyl-CoA or malonyl-CoA levels in the liver of transgene SSAT mice overexpressing SSAT, while both molecules were clearly reduced in the WAT of the same transgene mice. They have related this observation to the fact that the liver is clearly permeable to glucose, in comparison with other tissues. Therefore, it would be of interest to analyse the concentrations of acetyl and malonyl-CoA in the WAT of arginine-supplemented salmon in the future. Malonyl-CoA is known as an inhibitor of CPT-1, the expression of which was clearly up-regulated in the liver of fish fed the higharginine diet (Fig. 1(A)), indicating an increased oxidation of long-chain fatty acids in the liver. However, acetyl-CoA concentrations and SSAT activity were similar in the fish fed diets B and D and did not correlate with CPT-1 expression. This leads to the question whether the observed CPT-1 up-regulation is a true response to increased SSAT activity. A similar regulation of CPT-1 was not observed in the WAT. This could be due to the expression of different CPT-1 isoforms, as has been established in mammals, though the currently investigated CPT-1 isoform is the only one to be described in Atlantic salmon. Other studies have shown that arginine differentially regulates genes in the muscle and adipose tissue, up-regulating the lipolytic genes in the $\operatorname{WAT}^{(21,35)}$. This was not observed in the present study, though future studies will further examine the regulation of fatty acid metabolism in the WAT after arginine supplementation.

The production of polyamines requires decarboxylated SAM, which is synthesised from methionine and ATP, potentially depleting cells of these compounds. Still, methionine concentrations were not affected in the tissues examined (Table 5) and ATP concentrations were not affected in the liver by the high-arginine diets (Fig. 3(B)), which is similar to what has been observed by Jobgen et al. ${ }^{(35)}$. ATP 
concentrations were reduced in the liver of fish fed diet B, while there were no differences among the other dietary groups, indicating that the effect of arginine is not significant enough to deplete the cells of energy. SAM concentrations appeared to decrease in the liver of fish fed diets $\mathrm{C}$ and $\mathrm{D}$, compared with those fed diets $\mathrm{A}$ and $\mathrm{B}(P=0.08)$. The expression of SAMdc, the enzyme producing SAM, was not affected in the liver or WAT (Fig. 1(A) and (B)). As SAMdc is known to be negatively regulated by the increased spermidine and spermine levels ${ }^{(36)}$, this lack of effect on SAMdc expression can be seen in relation to the stable pools of both polyamines in the liver among the experimental dietary groups. Overall, SAM does not appear to be the limiting factor for polyamine turnover after arginine supplementation.

Increased free lysine concentrations were observed with increased dietary arginine supplementation in the plasma (Table 5), as well as increasing whole-body total lysine gain, even though lysine was equal in all the diets, which is opposite to what was expected as arginine efficiently inhibits the uptake of lysine from the lumen in salmon ${ }^{(6)}$. However, it is similar to what He et al. ${ }^{(37)}$ have observed in the plasma of pigs, which they suggested could be due to increased NO production in the lumen from arginine, killing micro-organisms, which in turn decreases the catabolism of amino acids by intestinal bacteria, increasing the uptake of amino acids ${ }^{(37)}$. The increase in whole-body total lysine content, however, may be related to the overall increased protein gain, incorporating lysine in myosin and actin, the bulking proteins of the muscle. Urea was observed at increasing concentrations in the muscle, possibly indicating arginine excess ${ }^{(38)}$, though liver and plasma urea remained unchanged. In general, arginine supplementation has limited adverse effects in fish, apart from possible oxidative stress caused by increased NO production and $\mathrm{H}_{2} \mathrm{O}_{2}$ produced via the oxidation of acetylated polyamines ${ }^{(13,35,38)}$. Future studies on arginine supplementation should therefore include markers for oxidative stress in salmon.

The present study demonstrated an increased turnover of polyamines in the liver, demonstrated with increased putrescine levels and SSAT activity and a declining pool of acetyl-CoA in the liver. Also, arginine supplementation affected amino acid metabolism in several tissues, increasing the concentrations of arginine metabolites. Growth results indicate arginine to be a promising supplement to enhance growth and protein deposition in Atlantic salmon, though future studies are required to further verify this, as well as to investigate how deposition is affected in different tissues in the post-smolt phase, the period when salmon deposit more lipid.

\section{Acknowledgements}

The present study was supported through the project 'Integrated amino acid requirement' financed by the Research Council of Norway (project no. 208352/E-40) and EWOS Innovation AS. The authors' responsibilities were as follows: A. A., M. E. and I. R. planned and designed the experiment and collected the samples. S. M. A., E. H. and M. E. collected the samples, analysed the data and interpreted the results; J. E. Z. designed the experiment and analysed the samples; S. M. A. and M. E. drafted the manuscript. All authors read and approved the final manuscript. The authors declare no conflict of interest.

\section{References}

1. Espe M, Lemme A, Petri A, et al. (2006) Can Atlantic salmon (Salmo salar) grow on diets devoid of fish meal? Aquaculture 255, 255-262.

2. Espe M, Lemme A, Petri A, et al. (2007) Assessment of lysine requirement for maximal protein accretion in Atlantic salmon using plant protein diets. Aquaculture 263, 168-178.

3. Torstensen BE, Espe M, Sanden M, et al. (2008) Novel production of Atlantic salmon (Salmo salar) protein based on combined replacement of fish meal and fish oil with plant meal and vegetable oil blends. Aquaculture 285, 193-200.

4. Rathore RM, Liaset B, Hevroy EM, et al. (2010) Lysine limitation alters the storage pattern of protein, lipid and glycogen in on-growing Atlantic salmon. Aquacult Res 41, e751-e759.

5. Fico ME, Hassan AS \& Milner JA (1982) The influence of excess lysine on urea cycle operation and pyrimidine biosynthesis. J Nutr 112, 1854-1861.

6. Berge GE, Bakke-McKellep AM \& Lied E (1999) In vitro uptake and interaction between arginine and lysine in the intestine of Atlantic salmon (Salmo salar). Aquaculture 179, 181-193.

7. Zhou F, Shao QJ, Xiao JX, et al. (2011) Effects of dietary arginine and lysine levels on growth performance, nutrient utilization and tissue biochemical profile of black sea bream, Acanthopagrus schlegelii, fingerlings. Aquaculture 319, 72-80.

8. Wu GY, Bazer FW, Davis TA, et al. (2009) Arginine metabolism and nutrition in growth, health and disease. Amino Acids 37, 153-168.

9. Pegg AE (2009) Mammalian polyamine metabolism and function. IUBMB Life 61, 880-894.

10. Mato JM, Corrales FJ, Lu SC, et al. (2002) S-Adenosylmethionine: a control switch that regulates liver function. FASEB J 16, $15-26$.

11. Janne J, Alhonen L, Pietila M, et al. (2006) Genetic manipulation of polyamine catabolism in rodents. J Biochem 139, $155-160$.

12. Flynn NE, Bird JG \& Guthrie AS (2009) Glucocorticoid regulation of amino acid and polyamine metabolism in the small intestine. Amino Acids 37, 123-129.

13. Pirinen E, Kuulasmaa T, Pietila M, et al. (2007) Enhanced polyamine catabolism alters homeostatic control of white adipose tissue mass, energy expenditure, and glucose metabolism. Mol Cell Biol 27, 4953-4967.

14. Pirinen E, Gylling H, Itkonen P, et al. (2010) Activated polyamine catabolism leads to low cholesterol levels by enhancing bile acid synthesis. Amino Acids 38, 549-560.

15. Cerrada-Gimenez M, Pietila M, Loimas S, et al. (2011) Continuous oxidative stress due to activation of polyamine catabolism accelerates aging and protects against hepatotoxic insults. Transgenic Res 20, 387-396.

16. Heljasvaara R, Veress I, Halmekyto M, et al. (1997) Transgenic mice overexpressing ornithine and S-adenosylmethionine decarboxylases maintain a physiological polyamine homoeostasis in their tissues. Biochem J 323, 457-462.

17. Jobgen W, Meininger CJ, Jobgen SC, et al. (2009) Dietary L-arginine supplementation reduces white fat gain and 
enhances skeletal muscle and brown fat masses in dietinduced obese rats. J Nutr 139, 230-237.

18. McKnight JR, Satterfield MC, Jobgen WS, et al. (2010) Beneficial effects of L-arginine on reducing obesity: potential mechanisms and important implications for human health. Amino Acids 39, 349-357.

19. Yao K, Yin YL, Chu WY, et al. (2008) Dietary arginine supplementation increases mTOR signaling activity in skeletal muscle of neonatal pigs. J Nutr 138, 867-872.

20. Tan B, Yin Y, Liu Z, et al. (2009) Dietary L-arginine supplementation increases muscle gain and reduces body fat mass in growing-finishing pigs. Amino Acids 37, 169-175.

21. Tan B, Yin Y, Liu Z, et al. (2011) Dietary L-arginine supplementation differentially regulates expression of lipidmetabolic genes in porcine adipose tissue and skeletal muscle. J Nutr Biochem 22, 441-445.

22. Valente LMP, Linares F, Villanueva JLR, et al. (2011) Dietary protein source or energy levels have no major impact on growth performance, nutrient utilisation or flesh fatty acids composition of market-sized Senegalese sole. Aquaculture 318, 128-137.

23. Espe M, Ruohonen K \& El-Mowafi A (2012) Effect of taurine supplementation on the metabolism and body lipid-to-protein ratio in juvenile Atlantic salmon (Salmo salar). Aquacult Res 43, 349-360.

24. Liaset B, Julshamn K \& Espe M (2003) Chemical composition and theoretical nutritional evaluation of the produced fractions from enzymic hydrolysis of salmon frames with Protamex (TM). Proc Biochem 38, 1747-1759.

25. Liaset B \& Espe M (2008) Nutritional composition of soluble and insoluble fractions obtained by enzymatic hydrolysis of fish-raw materials. Proc Biochem 43, 42-48.

26. Wang W, Kramer PM, Yang SM, et al. (2001) Reversed-phase high-performance liquid chromatography procedure for the simultaneous determination of $S$-adenosyl-L-methionine and $S$-adenosyl-L-homocysteine in mouse liver and the effect of methionine on their concentrations. J Chromatogr $B$ 762, 59-65.

27. Espe M \& Holen E (2013) Taurine attenuates apoptosis in primary liver cells isolated from Atlantic salmon (Salmo salar). Br J Nutr 110, 20-28.
28. Lin HJ, Lien YC \& Hsu CH (2010) A high-throughput colorimetric assay to characterize the enzyme kinetic and cellular activity of spermidine/spermine $N 1$-acetyltransferase 1 . Anal Biochem 407, 226-232.

29. Torstensen BE, Espe M, Stubhaug I, et al. (2011) Dietary plant proteins and vegetable oil blends increase adiposity and plasma lipids in Atlantic salmon (Salmo salar L.). Br J Nutr 106, 633-647.

30. Olsvik PA, Lie KK, Jordal AE, et al. (2005) Evaluation of potential reference genes in real-time RT-PCR studies of Atlantic salmon. BMC Mol Biol 6, 21.

31. Clemmensen C, Madsen AN, Smajilovic S, et al. (2011) L-Arginine improves multiple physiological parameters in mice exposed to diet-induced metabolic disturbances. Amino Acids 43, 1265-1275.

32. Berge GE, Sveier H \& Lied E (1998) Nutrition of Atlantic salmon (Salmo salar); the requirement and metabolic effect of lysine. Compar Biochem Physiol A: Mol Integr Physiol 120, 477-485.

33. Pegg AE (2008) Spermidine/spermine- $N(1)$-acetyltransferase: a key metabolic regulator. Am J Physiol Endocrinol Metab 294, E995-E1010.

34. Jell J, Merali S, Hensen ML, et al. (2007) Genetically altered expression of spermidine/spermine $N 1$-acetyltransferase affects fat metabolism in mice via acetyl-CoA. J Biol Chem 282, 8404-8413.

35. Jobgen W, Fu WJ, Gao H, et al. (2009) High fat feeding and dietary L-arginine supplementation differentially regulate gene expression in rat white adipose tissue. Amino Acids 37, 187-198.

36. Pegg AE, Xiong H, Feith DJ, et al. (1998) S-Adenosylmethionine decarboxylase: structure, function and regulation by polyamines. Biochem Soc Trans 26, 580-586.

37. He QH, Kong XF, Wu GY, et al. (2009) Metabolomic analysis of the response of growing pigs to dietary L-arginine supplementation. Amino Acids 37, 199-208.

38. Luiking YC \& Deutz NE (2007) Biomarkers of arginine and lysine excess. J Nutr 137, 1662S-1668S.

39. National Research Council (2011) Nutrient Requirements of Fish and Shrimp, Committee on the Nutrient Requirements of Fish and Shrimp. Washington, DC: The National Academies Press. 